\title{
Variedades nativas de papa: Tecnología tangible para afrontar el efecto causado por la helada y la sequía
}

\author{
J. Gabriel, J. Magne, R. García, J. Coca ${ }^{1}$
}

\begin{abstract}
RESUMEN
En el Centro Experimental Agropecuario Condoriri, Oruro, Bolivia, se evaluaron 61 accesiones de Solanum andigena, 14 of $S$. stenotonum y siete de $S . x$ juzepczukii, por resistencia a heladas. Los resultados mostraron que el número de estomas varía según el nivel de ploidia, observándose valores promedios de 60 estomas por campo óptico en S. x juzepczukii, 43 en S. stenotonum y 38 en S. andigena. El área estomática difiere entre especies: $S$. andigena mostró $515,3 \mu^{2}$, S. stenotonum tuvo $418 \mu^{2}, S . x$ juzepczukii mostró $237 \mu^{2}$. Hubo correlación entre la triple capa de empalizada en las células del parénquima y la resistencia a heladas en la especie S. x juzepczukii. En S. stenotonum se observó una doble empalizada en el parénquima y tuvo menor porcentaje de daño en follaje. $S$ andigena mostró una capa simple de empalizada y fue susceptible a las heladas. Las accesiones de S. x juzepczukii tienen tallos de pigmentación morada y hábito de crecimiento arrosetado y fueron las más resistentes a heladas. $S$. $x$ juzepczukii tuvo el más alto rendimiento $\left(9,8 \mathrm{t} \mathrm{ha}^{-1}\right)$ y $S$. andigena mostró el más bajo $\left(1,09 \mathrm{t} \mathrm{ha}^{-1}\right)$. Por otra parte, en el proyecto Papa Salud financiado por el Programa Iberoamericano de Ciencia y Tecnología para el Desarrollo (CYTED), se evaluó variedades nativas de papa por su reacción de resistencia o susceptibilidad a sequía. Los resultados mostraron que las variedades Solanum goniocalyx (2x), $S$. andigena (4x), la cruza S. stenotomum x S. goniocalyx y S. x chaucha fueron resistentes a este factor.
\end{abstract}

Palabras clave: células estomáticas, área estomática, tejido de empalizada, estrés abiótico

\section{Landraces potato: Tangible technology to meet the effect caused by frost and drought}

\begin{abstract}
In the Experimental Farming Condoriri Center in Oruro, Bolivia, 61 accessions of Solanum andigena, 14 of $S$. stenotonum and 7 of $S$. x juzepczukii species were tested by resistance to frosts. The results showed that the number of stomas varies according to the level of ploidy, being observed average values of 60 stomas by optical field in S. x juzepczukii, 43 in S. stenotonum and 38 in S. andigena. The stomatic area differed between species, S. andigena showed 515,3 $\mu^{2}$, S. stenotonum had $418 \mu^{2}$ and S. $x$ juzepczukii showed $237 \mu^{2}$. There was a correlation between the triple layer of fence in the cells of parenchyma and the resistance to frosts in the $S$ x juzepczukii species. In $S$. stenotonum, one double fence in parenchyma was observed, and it had minor percentage of damage in foliage. S. andigena showed a simple layer of fence and was susceptible to frosts. The accession 100 of $S$. x juzepczukii had the highest yield $\left(9.8 \mathrm{tha}^{-1}\right)$ and the accession 69 of $S$. andigena showed the lowest yield $\left(1.09 \mathrm{t} \mathrm{ha}^{-1}\right)$. Moreover under the project 'Papa Salud' funded by the 'Programa Iberoamericano de Ciencia y Tecnología para el Desarrollo' (CYTED), potato landraces were evaluated for their reaction of resistance or susceptibility to drought. The results showed that the varieties Solanum goniocalyx $(2 x)$, S. andigena $(4 \mathrm{x})$, the crosses $S$. stenotomum $x$ S. goniocalyx and S. $x$ chaucha $(3 \mathrm{x})$ were resistant to this factor.
\end{abstract}

Key words: stomatics cells, stomatic area, palisade tissue, abiotic stress

\footnotetext{
${ }^{1}$ Investigadores del Programa de Mejoramiento Genético de Papa, Fundación Promoción e Investigación de Productos Andinos (PROINPA), Casilla 4285, Cochabamba, Bolivia. j.gabriel@proinpa.org
} 


\section{Introducción}

Según el Instituto Nacional de Estadística de Bolivia (INE, 2008), la helada, la sequía y la granizada son tres de los eventos más importantes que han afectado a Bolivia durante varios años, pero en años recientes se han incrementado, reportándose por ejemplo en el año 2002, 351 casos de sequía, 66 casos de helada y 311 casos de granizada. En cambio en el año 2007, se han reportado 651 casos de sequía, 1.259 casos de helada y 695 casos de granizada, afectando principalmente los cultivos.

Así mismo, se ha reportado en el año 2002, 7.043 familias afectadas por la sequía, 2.402 por la helada y 6.225 por granizada. En el año 2007 se reportaron 37.638 familias afectadas por la sequía, 63.158 familias por la helada y 46.236 familias por la granizada (INE, 2008). Estas cifras están demostrando que algo está pasando con el clima y los efectos que está causando son dispares, no son o serán únicos entre departamentos, al interior de los departamentos y entre regiones del país. La amenaza a afrontar se caracteriza por sequías prolongadas, desertificación extrema, lluvias intensas, inundaciones, heladas, agotamiento de fuentes de agua, etc. (Magne, 2009).

Ante este desolador panorama los programas de mejoramiento genético de cultivos en general y de papa en particular tienen el gran reto de generar variedades mejoradas resistentes a sequía, helada y granizo, que sean capaces de adaptarse a los cambios paulatinos del clima y sean altamente productivas en el corto tiempo (precocidad), además de que éstas sean resistentes a factores bióticos emergentes.

Estos factores están gobernados por muchos genes (poligenes), que se expresan a través de múltiples características de reacción en la planta.

Estudiar las variedades nativas, silvestres y mejoradas y sus mecanismos morfológicos y citológicos de defensa son propósitos del Programa de Mejoramiento Genético de Papa de la Fundación PROINPA en Bolivia.

\section{Materiales y métodos}

Se han estudiado los mecanismos morfológicos y citológicos de defensa a la helada en especies como Solanum andigena $(4 \mathrm{x})$, S. stenotomum (2x) y $S . x$ juzepczukii (3x). Las variables de respuesta estudiadas fueron el rendimiento, la pigmentación del tallo, el tamaño de células estomáticas, el grosor de pared celular, el área estomática, el hábito de crecimiento de la planta, las capas de empalizada en el tejido parenquimatoso de las hojas y el porcentaje de tejido dañado (Choque et al., 2008). En otro estudio se evaluó la reacción de resistencia y susceptibilidad frente a la sequía en especies de S. andigena $(4 \mathrm{x})$, S. stenotomum $(2 \mathrm{x})$, S. phureja (2x) y S. chaucha (3x) (Gabriel et al., 2008).

\section{Resultados y discusión}

Recientes resultados obtenidos en Bolivia, mostraron que el número de estomas varía según el nivel de ploidía, observándose valores promedios de 60 estomas por campo óptico en $S$. $x$ juzepczukii, 43 en $S$. stenotonum y 38 en $S$. andigena. El área estomática difiere entre especies: $S$. andigena mostró $515,3 \mu^{2}, S$. stenotonum tuvo $418 \mu^{2}$, S. x juzepczukii mostró $237 \mu^{2}$ (Choque et al., 2008). Hubo correlación entre la triple capa de empalizada en las células del parénquima y la resistencia a heladas en la especie S.x juzepczukii. En S. stenotonum se observó una doble empalizada en el parénquima, y tuvo menor porcentaje de daño en follaje. $S$ andigena mostró una capa simple de empalizada y fue susceptible a las heladas (Choque et al., 2008). Las accesiones de $S$. x juzepczukii evaluadas mostraron tallos de pigmentación morada y hábito de crecimiento arrosetado y fueron las más resistentes a heladas. Una accesión de $S$. x juzepczukii tuvo los más altos rendimientos $\left(9,8 \mathrm{t}^{\circ} \mathrm{ha}^{-1}\right)$ y una accesión de $S$. andigena mostró el más bajo rendimiento $(1,09$ $\left.\mathrm{t} \cdot \mathrm{ha}^{-1}\right)$.

La Fundación PROINPA en Bolivia ha logrado unas 200 familias de 40.000 plántulas, usando además otras especies silvestres muy resistentes como S. chomatophilum. S. commersoni, S. megistacrolobum y $S$. sanctae-rosae, de las que 
se han seleccionado unos cuatro clones con resistencia a las heladas a $-4^{\circ} \mathrm{C}$ y buena producción (Estrada, 2000).

Para el caso de sequía, el estudio mostró que especies cultivadas de $S . x$ chaucha $(3 x)$, un híbrido entre stn $x$ gon $(2 x)$, S. goniocalyx $(2 x)$ y $S$. andigena $(4 x)$ fueron resistentes, manifestando a las dos semanas de punto de marchitez permanente (PMP) plantas ligeramente marchitas y/o plantas iguales al testigo con riego, con pérdidas de agua que van desde 1,06 a 1,36 $\mathrm{kg}$, respecto de la variedad India, que fue la más susceptible a la sequía, la misma que mostró en el mismo periodo $100 \%$ de marchitez y pérdida de agua de 8,69 kg. La variedad Waych'a mostró ser resistente (Gabriel et al., 2008; Coca, 2010). En este estudio no se analizaron los mecanismos morfológicos.

Se debe mencionar que en realidad la helada parece ser un fenómeno asociado con la sequía, porque cuando ocurre una helada comienza la congelación y se forma hielo extracelular.

El agua se moviliza desde adentro hacia afuera de la célula, los solutos y componentes celulares adquieren una alta concentración y causan un estrés prolongado a las células, que causa la muerte eventual de las células por la desnaturalización de las proteínas o de las uniones químicas y por la destrucción de las proteínas de la membrana celular (Estrada, 2000).

Varios factores están asociados con la resistencia a helada y sequía, en la que están definitivamente involucrados muchos genes (poligénico), por lo que su mejoramiento es lento $\mathrm{y}$ laborioso, porque se requieren frecuentes retrocruzamientos y selección recurrente; además, se debe manejar poblaciones altas de progenies para tener la oportunidad de lograr algunas selecciones interesantes y que potencialmente sean potenciales variedades futuras.

\section{Agradecimientos}

Al Programa Iberoamericano de Ciencia y Tecnología para el Desarrollo (CYTED)
407PIC0306 por el financiamiento para ejecutar el proyecto Papa Salud.

\section{Literatura citada}

Estrada, N. 2000. La biodiversidad en el mejoramiento genético de la papa. CIP-IPGRIPRACIPA-IBTA-PROINPA-COSUDE-CID, La Paz, Bolivia. 372 p.

Choque, E., Espinoza, R., Cadima, X., Zeballos, J., Gabriel, J. 2008. Resistencia a helada en germoplasma de papa nativa de Bolivia. Revista Latinoamericana de la Papa 14 (1): 24-32.

Coca, J. 2010. Variedades nativas de papa (Solanum tuberosum L.) evaluadas por su reacción de resistencia y/o susceptibilidad a factores bióticos y abióticos. Tesis de grado para optar al grado de licenciada en Biología en la Universidad Mayor de San Simón (UMSS), Cochabamba, Bolivia. 70 p.

Gabriel, J., Coca, J., Angulo, A., Franco, J., Plata, G. 2008. Germoplasma nativo de papa evaluado por su reacción de resistencia y/o susceptibilidad a factores bióticos y abióticos. Páginas 53 - 60 En: E. Ritter y J.I. Ruíz de Galarreta (Eds.). Avances en Ciencia y Desarrollo de la Patata para una Agricultura Sostenible. III Congreso Iberoamericano en Patata. Octubre 05 al 10, 2008. Vitoria - Gasteíz, Euskadi, España.

Instituto Nacional de Estadística de Bolivia (INE). 2008. Bolivia: Eventos adversos de origen natural reportados, según tipo de evento, 2002-2008.

http://www.ine.gov.bo/indice/visualizador.aspx? $\mathrm{ah}=$ PC80601.HTM. Consulta: Julio - 2010.

Magne, J. 2009. Herencia de la resistencia genética de arveja (Pisum sativum L.) al anegamiento. Tesis de grado para optar al grado de licenciado en Ingenieria Agronómica de la Facultad de Ciencias Agrícolas, Pecuarias, Forestales y Veterinarias "Martín Cárdenas, Universidad Mayor de San Simón (UMSS), Cochabamba, Bolivia. 83 p. 